\title{
The depth and breadth of multiple perceptual asymmetries in right
} handers and non-right handers

Karlsson, Emma M; Johnstone, Leah T; Carey, David P

\section{Laterality}

DOI:

$10.1080 / 1357650 X .2019 .1652308$

Published: 02/11/2019

Peer reviewed version

Cyswllt i'r cyhoeddiad / Link to publication

Dyfyniad o'r fersiwn a gyhoeddwyd / Citation for published version (APA):

Karlsson, E. M., Johnstone, L. T., \& Carey, D. P. (2019). The depth and breadth of multiple perceptual asymmetries in right handers and non-right handers. Laterality, 24(6), 707-739. https://doi.org/10.1080/1357650X.2019.1652308

\footnotetext{
Hawliau Cyffredinol / General rights

Copyright and moral rights for the publications made accessible in the public portal are retained by the authors and/or other copyright owners and it is a condition of accessing publications that users recognise and abide by the legal requirements associated with these rights.

- Users may download and print one copy of any publication from the public portal for the purpose of private study or research.

- You may not further distribute the material or use it for any profit-making activity or commercial gain

- You may freely distribute the URL identifying the publication in the public portal ?
}

Take down policy

If you believe that this document breaches copyright please contact us providing details, and we will remove access to the work immediately and investigate your claim. 


\section{The depth and breadth of multiple perceptual asymmetries in right handers and non-right handers}

Emma M. Karlsson $^{\mathrm{a}}$, Leah T. Johnstone ${ }^{\mathrm{b}}$ and David P. Carey ${ }^{\mathrm{a} *}$

${ }^{a}$ Perception, Action and Memory Research Group, School of Psychology, Bangor University, Bangor, UK; ${ }^{b}$ Sports Psychology Group, UCFB Wembley, London, UK

*School of Psychology, Bangor University, Bangor, UK, LL57 2AS, email: d.carey@bangor.ac.uk 


\section{The depth and breadth of multiple perceptual asymmetries in right handers and non-right handers}

Several non-verbal perceptual and attentional processes have been linked with specialization of the right cerebral hemisphere. Given that most people have a left hemispheric specialization for language, it is tempting to assume that functions of these two classes of dominance are related. Unfortunately, such models of complementarity are notoriously hard to test. Here we suggest a method which compares frequency of a particular perceptual asymmetry with known frequencies of left hemispheric language dominance in right handed and non-right handed groups. We illustrate this idea using the greyscales and colourscales tasks, chimeric faces, emotional dichotic listening, and a consonant-vowel dichotic listening task. Results show a substantial "breadth" of leftward bias on the right hemispheric tasks and rightward bias on verbal dichotic listening. Right handers and non-right handers did not differ in terms of proportions of people who were left biased for greyscales/colourscales. Support for reduced typical biases in non-right handers was found for chimeric faces and for CV dichotic listening. Results are discussed in terms of complementary theories of cerebral asymmetries, and how this type of method could be used to create a taxonomy of lateralized functions, each categorized as related to speech and language dominance, or not.

Keywords: handedness; cerebral dominance; dichotic listening; chimeric faces; greyscales 
Perceptual bias tests have been used to quantify asymmetries since at least the 1950s (e.g. Bryden, 1960; Heron, 1957; Mishkin \& Forgays, 1952). Many of the biases obtained were thought to be the result of underlying cerebral asymmetries; however, it was difficult to find evidence to confirm such relationships in those pre-neuroimaging days. Other paradigms relevant for establishing links to brain asymmetry required testing so called “split-brain" patients (Gazzaniga \& Sperry, 1967), or patients with unilateral brain damage (Bryden, Hécaen, \& DeAgostini, 1983; Kimura, 1983; Newcombe \& Ratcliff, 1973). Another alternative was to compare right handers and non-right handers on a "lateralized" test or tests, where the obvious prediction was a reduced asymmetry in the non-right handed group. This prediction follows the generally-accepted reduction in the proportion of non-right handed individuals with left hemispheric specialization for language, which, in those days, was assessed in groups of patients of known handedness with unilateral brain damage, or using the Wada technique with epileptic patients (Branch, Milner, \& Rasmussen, 1964; Rasmussen \& Milner, 1977).

Hundreds of such behavioural perceptual bias papers comparing handedness groups have been published, usually reporting the aforementioned reduction in magnitude (but not a change in direction) of asymmetry in the non-right handed, relative to right handed, group. These papers, however, almost exclusively produce statistical analyses focused on central tendency, comparing average performance of each group on the asymmetry task in question. Fortunately, some of the older works also tended to report individual participant data in tables or figures, which allows for estimating the proportions of the two handedness groups that showed the typical or atypical bias. Data of this kind could be remarkably useful. It can be compared with the well-established proportions for speech and language dominance in right handers and non-right handers (Carey \& Johnstone, 2014; Hécaen \& Sauguet, 1971; Knecht et al., 2000; Rasmussen \& 
Milner, 1977). These data can also be used to understand the reduced asymmetries in nonright handed groups more fully. Weakened asymmetries in most non-right handed participants (relative to the right handers) would have quite a different interpretation than if the reduction is accounted for by a small subgroup of non-right handers with reversed asymmetries. This distinction is of crucial importance.

Unsurprisingly, language-related asymmetry has been the focus for behavioural studies comparing right handers and non-right handers (Hugdahl \& Franzon, 1985; Isaacs, Barr, Nelson, \& Devinsky, 2006). Nevertheless, a small number of highly-cited experiments seemed to establish that some cerebral asymmetries favouring the right hemisphere result in a similar reduction in degree of lateralization between non-right handers and right handers as that found for language. In other words, reductions, on average, in the right hemispheric bias in the non-right handers were found. For example, the use of centrally-positioned chimeric faces, comprising of one emotive hemiface and one neutral hemiface, have been found to produce preferences for emotions shown in the left visual field that were reduced in the non-right handed group (e.g. Gilbert \& Bakan, 1973; Heller \& Levy, 1981; Levy, Heller, Banich, \& Burton, 1983; Roszkowski \& Snelbecker, 1982). These experiments, despite power issues in some of them, had considerable face validity, given the reduced left sided bias, paralleling the known reduction in leftward asymmetry for speech and language in the non-right handed participants.

Some theories propose that language asymmetry causes a non-linguistic capability, such as face processing, to depend more on the non-language dominant hemisphere. For example, contemporary versions of these "crowding hypotheses" link the acquisition of reading to specialization of visuoperceptual circuits in the same hemisphere as that which is innately predisposed to oral and spoken language. As reading 
develops, non-linguistic visual perceptual abilities that depend on foveal vision then become more specialised in the non-language dominant hemisphere (Behrmann \& Plaut, 2015; Centanni et al., 2018; Dehaene et al., 2010). From this perspective, testing nonright handers on right hemispheric specializations is unnecessary, as any reduced right hemispheric bias in this group would be accounted for by the small proportion of nonright handers who would be bilateral or right hemisphere dominant for language. In theory, if face processing asymmetry is related to speech and language dominance in some causal way, then right hemispheric advantages for faces would parallel left hemispheric dominance for speech and language but in the opposite hemisphere. This argument should also hold true for any cerebral asymmetry that is "yoked" to hemispheric dominance for language. The list of possibilities is considerable, but for this set of experiments, we will restrict our "right hemispheric" focus to face processing, processing of emotional prosody, and visuospatial attention.

Since the early work on face processing, other behavioural asymmetries favouring the left visual field in right handers have been revealed, but non-right handers are almost never tested. Most notably, visuospatial attention is one class of asymmetry well known as depending more on the right cerebral hemisphere, deduced primarily from neuropsychological studies of hemispatial neglect. Unfortunately, neglect is infrequently studied in non-right handers (a few case reports excepted: Dronkers \& Knight, 1989; Padovani et al., 1992). Nevertheless, a few behavioural tasks assessing right hemispheric attentional mechanisms have been proposed and could be used to contrast right handed and non-right handed groups.

One such attentional bias task was developed by Mattingley, Bradshaw, Nettleton, and Bradshaw (1994), as part of a study on mechanisms underlying hemispatial neglect. Their "greyscales" task requires individuals to choose which of two vertically-arranged 
horizontal bars with a black to white gradient is darker (see Figure 1). The bars are in fact mirror-images of one another, such that participants should chose the bar with the left side darkest and the right side darkest approximately an equal number of times. Instead, they found a small but significant mean bias to select the bar with the darker end on the left, which has been replicated in several laboratories (Friedrich \& Elias, 2014; Nicholls, Bradshaw, \& Mattingley, 1999; Tant, Kuks, Kooijman, Cornelissen, \& Brouwer, 2002; Tomer et al., 2012). What is most interesting about these data is the "breadth" (i.e. how many, rather than "depth", how biased on average) of the asymmetry in Mattingley et al. (1994): $80 \%$ of the right handed control participants had a leftward bias.

This breath of left-sided bias can be estimated from other experiments, even when the required frequency data is not presented in the paper per se. A recent study by Innes, Burt, Birch, and Hausmann (2016) contrasted side biases on emotional chimeric faces with those obtained in the greyscales task in a sample of 59 right handers. Although the study was mainly motivated by examining if the leftward bias in the traditional chimeric face paradigm could be largely accounted for by a general attentional bias, their data provide an opportunity to test the breadth of left-sided greyscales bias in an independent and slightly larger sample of right handers. Even though the proportions were not provided in the original paper, these colleagues were kind enough to share their raw data with us. Like Mattingley et al. (1994), their data reveals that a high percentage (85\%) of their right handed participants had the typically obtained left sided bias in greyscales. This proportion suggests that greyscales may tap into a function or functions that "antilocalise" (i.e. localise to the other hemisphere) relative to language. Of course, this logic could be extended to other visual and non-visual asymmetries that are thought to depend more on mechanisms in the right hemisphere. 
In fact, one such function is intimately associated with language, but is usually not considered in crowding hypotheses of hemispheric asymmetries. There is a large parallel literature in the auditory domain that links speech and some (but not all) properties of language to the left hemisphere, but the processing of emotional prosody to the right hemisphere. For example, Hughlings-Jackson (1879) published some of the earliest observations of patients with profound language disturbance who often retained the abilities to laugh, smile, and cry. Many years later, the neuropsychological evidence on exactly what elements of acoustic signals are processed preferentially by the right hemisphere is not yet conclusive, but this literature is remarkably consistent in the suggestion that emotional prosody at least is handled preferentially by the non-speech hemisphere (Meyer, Alter, Friederici, Lohmann, \& von Cramon, 2002; Ross, 1981; Sammler, Grosbras, Anwander, Bestelmeyer, \& Belin, 2015; reviewed in Paulmann, 2015; Wittemann et al., 2011; although see van Lackner \& Sidtis, 1992).

The evidence for the perceptual lateralization of emotional prosody comes from studies utilizing the dichotic listening technique in healthy participants. Bryden and MacRae (1989) presented dichotically-paired words spoken in an emotional or neutral tone and asked their 32 right handed participants to indicate if a target emotion was present or absent from the dichotomous pair. They found that $86 \%$ of participants were better at detecting the emotional tone when it was presented to their left ear. Several other studies have also found that right handers were, on average, better at detecting the emotional prosody when presented to the left ear (Enriquez \& Bernabeu, 2008; Grimshaw, Kwasny, Covell, \& Johnson, 2003; Shipley-Brown, Dingwall, Berlin, YeniKomshian, \& Gordon-Salant, 1988; Voyer, Bowes, \& Soraggi, 2009; Voyer, Russell, \& McKenna, 2002). Studies with non-right handed participants are rare, and many only include a small number of participants (e.g. Donnot \& Vauclair, 2007; Elias, Bryden, \& 
Bulman-Fleming, 1998; McNeeley \& Netley, 1998; McNeely \& Parlow, 2001; Turnbull \& Bryson, 2001).

One exception to the omission of non-right handers is Bryden, Free, Gagné and Groff (1991) who recruited 48 right handed and 48 non-right handed participants. They, surprisingly, found that the left ear advantage (LEA) for emotional prosody processing was increased in non-right handed sample relative to right handers; $68 \%$ of right handers and $74 \%$ of non-right handers had a LEA. Grimshaw (1998) recruited 32 right handers and 32 non-right handers, but found that non-right handers had an overall right ear advantage (REA); $59 \%$ of right handers and only $40 \%$ of non-right handers had a left ear advantage. The discrepancy between these two studies suggests that additional, ideally large samples, of right handers and non-right handers would be desirable.

In summary, there is good evidence, especially from right handed samples, that attention, emotional prosody and some aspects of face processing tend to depend more on the right hemisphere than the left. How these functions lateralize in non-right handers, at least for attention and emotional prosody, is less clear. If it is indeed the case that performance on any tests that tend to favour the right hemisphere is indicative of a function that localizes to the non-language hemisphere, the difference between these two groups, as suggested by speech and language cerebral dominance, should be about a 20$25 \%$ reduction in the proportion of non-right handers who show the typical asymmetry, (if such a test assesses the underlying function perfectly; Carey \& Johnstone, 2014). Differences in the predicted direction in the proportion of the sample showing the asymmetry would provide initial strong prima facie evidence for complementarity of that function with speech/language asymmetry. No difference between the groups would suggest that the function is lateralised independently of speech and language. Surprisingly 
few theorists have ever made such arguments, in part because the data on non-right handers is sparse.

As part of a larger, long-term project on measuring multiple behavioural, perceptual and cerebral asymmetries, we have administered three different types of perceptual tests thought to depend more on the right hemisphere to relatively large samples of right handed and non-right handed participants, as well as a perceptual measure of language asymmetry in the same individuals. For assessing attentional asymmetry, we selected the greyscales task, given its ease of administration and scoring. In a second study, we created a variant of the task, "colourscales", which we used to investigate the same questions in a second sample of right handed and non-right handed participants. For face processing, we used two different variants of a chimeric face task. We also developed an in house four-block emotional prosody dichotic listening task, which we streamlined to a two-block version. As a measure of language asymmetry, we used the Bergen consonant-vowel (CV) dichotic listening task, again, given ease of administration and its propensity to deliver robust right ear advantages (Hugdahl et al., 2009). Finally, to confirm and extend some of the observations on these group differences in our lab, we meta-analysed available frequency data on verbal dichotic listening, chimeric faces, emotional dichotic listening and greyscales/colourscales.

We predicted that for all four tasks, both right handers and non-right handers would show group level biases towards the typical response (that is, the direction that corresponds to "typical" cortical organisation) and that the magnitude of the side bias would be greater in the right handers. The evidence for this difference has already been established in dichotic listening (Carey \& Johnstone, 2014; Westerhausen \& Kompus, 2018), and some evidence suggests it is likely for chimeric faces (e.g. Gilbert \& Bakan, 1973; Roszkowski \& Snelbecker, 1982; Voyer, Voyer, \& Tramonte, 2012). We also 
predicted that the percentage of the non-right handed sample giving this typical response would be reduced, indicating a larger percentage of individuals with reversed asymmetries.

\section{Experiment 1. Perceptual asymmetry study 1}

\section{Participants}

Participants were 181 Bangor University undergraduates, postgraduates and staff members recruited opportunistically and via a student participation panel. Seventy-six (44 females) were classified as right handed due to right-handed writing, no report of handedness switch, and a modified Waterloo Handedness Questionnaire (WHQ; Steenhuis $\&$ Bryden, 1989) score above +10 on a 30 -point, 15 item scale $(+2$ strong right hand preference to -2 strong left hand preference). The 105 (59 female) non-right handers were left handed for writing, scored less than +10 on the modified WHQ, or reported being forced to switch to writing with their right hand in infancy. Right handers had a mean age of $26.36(S D=8.12)$ and had an average WHQ score of +28.03 $(S D=2.77)$; the mean age of the non-right handers was $25.41(S D=9.18)$, and average WHQ -17.39 $(S D=14.42)$.

\section{Apparatus and materials}

The greyscales task was carried out on a $133.5 \times 100.5 \mathrm{~cm}$ bespoke glass top table $(81.5 \mathrm{~cm}$ in height), and stimuli were projected to the underside using a short-throw Sanyo PDGDWL2500 Multimedia Projector. The projector mirrored a computer running E-Prime 2.0 Professional (Psychology Software Tools, Pittsburgh, PA) to present the stimuli. E-Prime 
2.0 Professional was also used to present the stimuli in the CV dichotic listening task. The auditory stimuli were presented through a pair of Beyerdynamic (DT770 PRO 80 OHM) headphones. A decibel meter was used to ensure the two channels were matched for sound pressure level (balanced at $+/-0.1 \mathrm{~dB}$ ).

\section{Stimuli}

CV dichotic listening

The stimuli for the CV dichotic listening paradigm (Hugdahl et al., 2009) were kindly shared with us by Dr Rene Westerhausen (https://www.sv.uio.no/psi/personer/vit /renew/index.html?vrtx=tags). The consonant-vowel syllables are paired presentations of the six stop-consonants /b, d, g, p, t, k/ with the vowel /a/ to form six consonant-vowel (CV) syllables: /ba/, /da/, /ga/, /pa/, /ta/, /ka/. These were combined in pairs and played in each sound channel (eg. /pa/-/ga/), resulting in 36 stimulus pairings including homonyms. The stimuli were presented three times in three separate blocks (108 trials in total). Each block contained all possible syllable pairings including homonyms. The three-block version of this task is traditionally used to measure cognitive control by directed attention, comprising of three conditions; a "non-forced attention" condition and two "forced right/ left" conditions, where the participants are specifically asked to focus their attention on the right and left ear (see e.g. Hugdahl \& Andersson, 1986; Hugdahl et al., 2009). In the current experiment, all bocks were given under non-forced conditions to calculate an ear advantage score from a larger number of trials. The 18 trials of homonyms were excluded from laterality calculations.

Greyscales task

The greyscales stimuli (available from http://www.flinders.edu.au/sabs/psychology/research/labs/brain-and-cognition- 
laboratory/the-greyscales-task.cfm) consisted of 40 images of two left-right mirror reversed brightness gradients, defined by a black rectangle and presented on a white background (see Figure 1). One end of each bar was white, the other was black, and in between shading transitioned from black to white. Two different bar lengths were used; 20 of the bars were $45.5 \mathrm{~cm}$ and 20 were $54.5 \mathrm{~cm}$ (both $9 \mathrm{~cm}$ thick). As participants were standing, precise distances to the stimuli are not possible; we estimate a visual angle of approximately 38 degrees horizontally for the wider stimulus pairs. For each bar pair, half of the stimuli with the darker end on the left were presented as the top bar, and half as the bottom bar.

\section{[Insert Figure 1 about here]}

\section{Procedure}

CV dichotic listening

Participants were given a set of headphones and were instructed they would hear a pair of syllables presented in each trial. They were instructed to report back the syllable they heard or if it seemed like they heard two different sounds, the one they heard best or most clearly. They were also instructed that they should try and center their attention to their best ability, and not focus their attention by listening to the syllables presented to a particular ear. The participants were also told that they may not report all syllables an equal amount of time, and not to worry if they reported the same syllable several times in a row. The participants were encouraged not to spend time thinking about the sounds, but to report one back as soon as the sound had been presented by verbally reporting the 
sound and to point to it on a response sheet that was given at the start of the experiment. The experimenter entered the response using keyboard which triggered the next trial. A rest period was offered between each block.

Greyscales task

The participants were positioned at the centre of the horizontal edge of the table (standing). Each trial began with the presentation of the greyscale stimulus under freeviewing conditions, which remained on the table screen until the participants responded, by verbally stating which bar, by voicing "top" or "bottom", appeared darker to them. They were instructed to respond as quickly as possible. Following the response, the experimenter would input the response using a keypress, removing the current stimulus and starting the next trial after a 1000ms inter-trial interval.

\section{Results}

We calculated a laterality index $(\mathrm{LI})$ for each participant, $\mathrm{LI}=(\mathrm{R}-\mathrm{L}) /(\mathrm{R}+\mathrm{L}) * 100$, where $\mathrm{R}$ equals the number of stimuli where the chosen member of the pair had the dark side of the gradient on the right, or the syllable presented to the right ear. Therefore, response bias scores range from -100 to +100 , with negative scores reflecting a leftward bias/ left ear advantage (LEA) and positive scores reflecting a rightward bias/ right ear advantage (REA). A score of 0 reflects no bias (i.e. the participant reported bars with the darker side to the left and right equally).

CV dichotic listening

The predicted right ear advantage was found for both right handers $(M=+25.40$, 
$S D=23.33), t(74)=9.43, p<.001$, and non-right handers $(M=+17.91, S D=26.59)$, $t(103)=6.87, p<.001$. Right handed participants were, on average, found to have higher LI scores as compared to non-right handers, $t(177)=-1.95, p=.026$ (one-tailed), $d=$ 0.30. The percentages showing right ear advantages in each group were compared using a z-test: $86.7 \%$ of the right handers $(65 / 75)$ and $77.9 \%$ of the non-right handers $(81 / 104)$ had leftward biases, but these did not differ significantly, $z=1.50, p=0.68$ (one-tailed).

Greyscales task

The hypothesized left-sided bias was found for right handers $(M=-23.22, S D=$ $36.98), t(75)-5.48, p<.001$, and non-right handers $(M=-22.77, S D=38.50), t(104)-$ $6.06, p<.001$, however, no significant difference between mean LI scores were found ( $p$ $=.937)$. Two right handers $(2.6 \%)$ and five non-right handers $(4.8 \%)$ had LIs of 0. For our frequency analysis, only participants with a directional bias were included. The percentages showing leftward biases in each group were compared: $77.0 \%$ of the right handers (57/74) and 71.0\% of the non-right handers (71/100) had leftward biases but these did not differ significantly, $z=0.89, p=.187$ (one-tailed). No correlation was found between LIs in the CV dichotic listening task and the greyscales task $(r=.02, p=.807)$.

\section{Interim discussion}

Despite our suggestion that greyscales might "anti-localise" with speech and language function, right handers and non-right handers did not differ in the mean leftward bias or in terms of the percentage of people in each group showing a leftward bias, although both types of measure were in the predicted direction at least. For CV dichotic listening, the means differed significantly in the predicted direction although the proportions did not. 
For greyscales, the proportional bias in the right handed sample was marginally lower than seen in Mattingley et al. (1994) and Innes et al. (2016). We had anecdotal reports from a relatively small proportion of participants (in debriefing typically or immediately after we finished the test) that suggested they had deduced that the stimuli were identical but reversed. We did however not record these systematically. We decided to add another visual variable (in addition to line length) to the task, to help disguise the manipulation somewhat better. At this stage, our working hypothesis was greater breadth of left sided bias in our new variant. We made no plans to systematically compare the two tasks directly. Finally, as part of our expanding repertoire of neuroimaging experiments (in progress) we also added perceptual measures related to asymmetrical processing of emotional prosody and of faces.

\section{Experiment 2. Perceptual asymmetry study 2}

\section{Participants}

Participants were 453 Bangor University undergraduates, postgraduates and staff members recruited opportunistically and via a student participation panel. Handedness group classification was as reported for Experiment 1. Two hundred and sixty-three (184 females) were classified as right handed, and 190 (136 females) as non-right handed. Right handers had a mean age of $22.22(S D=5.01)$; non-right handers a mean age of $24.66(S D=9.24)$. The average WHQ score for the right handed group was +26.26 (SD $=4.13)$, and $-19.67(S D=13.59)$ for the non-right handed group. Twenty-nine of the participants had been tested in Experiment 1 but were tested a minimum of 17 months later. 


\section{Apparatus}

The tasks were carried out on a desktop computer with a 1920x1080 monitor resolution and a refresh rate of $60 \mathrm{~Hz}$, running E-Prime 2.0 Professional (Psychology Software Tools, Pittsburgh, PA) to present the stimuli. A chinrest positioned at $50 \mathrm{~cm}$ from, and centred to, the monitor was used for all visual tasks. The auditory stimuli were presented through a pair of Beyerdynamic (DT770 PRO 80 OHM) headphones.

\section{Stimuli}

Chimeric faces 1.0

The stimuli for this experiment were kindly provided to us by Dr Michael Burt (https://www.dur.ac.uk/psychology/staff/?id=1942), and are a considerable improvement to chimeras made by splicing photographs together as has been frequently the case in the literature. The faces consisted of symmetrical average images created from four male and four female faces (see Burt \& Perrett, 1997, and Innes et al., 2016, for more information). Four emotional facial expressions were used: anger, disgust, happiness, and sadness. The faces were vertically split down the middle of the face and paired so that one emotive hemiface was attached to another and then blended at the midline. These were paired in all possible combinations creating 16 individual stimuli presented to the participant twice in a total of 32 trials.

\section{Chimeric faces 2.0}

Stimuli for this experiment were from the same database as the previous chimeric faces task. Six emotional expression were used; happy, sad, disgust, anger, surprise and fear. This time, each chimeric face stimuli consisted of one emotive expression paired with one neutral expression (see Figure 2). Two versions of each face pair were used, one 
with the emotive expression on left side, and one with emotive expression on right side, resulting in a total of 12 images. Stimuli were presented in pairs, centered $1^{\circ}$ of visual angle above and below central fixation. Each pair was presented four times, resulting in a total of 48 trials.

[Insert Figure 2 about here]

$\mathrm{CV}$ dichotic listening

The CV dichotic listening stimuli were the same as in Experiment 1.

Colourscales task

Stimuli for the colourscales task consisted of images of two left-right mirror reversal colour gradient bars, presented on a white background. Bars between white and four different colours respectively were used; blue, green, purple and red (see Figure 3 for examples). Each colour was presented at two different lengths, at a visual angle of $28^{\circ}$ and $34^{\circ}$. Each bar pair was presented twice so that the bars with the left to right colour/white gradient was shown at the top in one trial and at the bottom in one trial. Four black and white greyscales-like stimuli were also included, resulting in a total of 20 stimulus pairs. The horizontal midline of each stimulus pair was aligned with the screen's centre. Each stimulus pair was presented twice; once targeted for the colour gradient, and once targeted for the white gradient, resulting in a total of 40 trials. 
Emotional dichotic listening long version (EmoDL long)

The stimuli for this task were four monosyllabic words; ball, fall, call and mall. These words were spoken in four emotional tones; happy, sad, fear and anger. The stimuli for this task were recordings from four actresses reading each word in the four emotional tones, and were normalised in energy (root mean square). Each word/emotion combination were paired with each other with the constraint that two different words and two different prosodies were present in each trial. The same actress generated both words in any pairing. This resulted in a total of 144 stimulus pairs. The stimulus pairs were chosen so that each actress appeared an equal number of times, both for each word and each emotional prosody. Every matched pair was always the identical stimuli but reversed, so that one member of each identical pairing would be presented once to the left ear and once to the right ear.

Emotional dichotic listening short version (EmoDL short)

One issue with dichotic listening tasks is stimulus dominance; when one stimulus in the pair is so salient that participant always report back that item regardless of the ear it is presented to. Although this does not influence the direction of a person's ear advantage, it adds noise, thus, reducing the overall ear advantage (Grimshaw, McManus \& Bryden, 1994). By reducing the effect of dominant pairs, a "purer" ear advantage can be obtained. For the shorter version, we considered stimulus dominance effects reported in the long version. This was carried out by analysing each stimulus pair from each participant who took part in the long version, and excluded pairs in which one item was reported back in $70 \%$ or more of the participants regardless of the ear it was presented to. Eight items were found to be dominant from this analysis. 
In addition, a goal was to create an emotional dichotic listening task with a short administration time. The original four-block version of EmoDL was organised so that two of the blocks contained the same item pairings but reversed for the ears. This meant that all stimuli could be divided into two sets, each set containing half of the items. Since a strong correlation for LI ear advantages was found between the two blocks ( $r=.81, p<$ $.001, N=134)$, half of the task was used for the short version. The final version consisted of 72 trials split over two blocks and were balanced as well as possible regarding number of trials for each actress, word and emotion. As in the previous version, a different word and a different emotional tone was presented to each ear in each trial. Every matched pair was always the identical stimuli but reversed, so that one member of each identical pairing would be presented once to the left ear and once to the right ear.

\section{Procedure}

Chimeric faces 1.0

The participants were seated in front of the computer, positioned in the chinrest. They were instructed to focus on the fixation cross shown in the center of the screen at all times. Each trial started with a fixation cross for $1000 \mathrm{~ms}$, followed by the presentation of the emotional chimeric face for $400 \mathrm{~ms}$. The participants were asked to verbally report to the experimenter the emotion seen in the face, and informed that it was a choice out of the four present emotions. The experimenter inputted the response using a key press on keyboard which triggered the next trial. The trials were presented in a randomized order.

Chimeric faces 2.0

Participants were positioned in the chinrest. In each trial a question was presented for $2000 \mathrm{~ms}$, instructing the participants about which emotion they were responding to. 
This was followed by the presentation of the face pair. The participants were instructed to indicate the face that displayed the target emotion more. To respond, participants pressed the " $\mathrm{T}$ " key indicating the top face or the " $\mathrm{B}$ " key indicating the bottom face. Participants were free to attend to both faces; however, were asked to go with their initial reaction and to report their decision as quick as possible. Once the response was registered the next trial was initiated immediately.

Colourscales task

Participants were positioned in the chinrest. Each trial began with a question centred on the screen for $1500 \mathrm{~ms}$, such as “Greener?", "Whiter?”, or “Bluer?”, informing which colour to respond to in the trial. The stimulus presentation of the associated colourscale bars followed and remained on the screen until the participants responded by pressing the "T" key on the keyboard indicating the top bar, or the "B" key indicating the bottom bar, initiating the next trial. The presentation was randomized for each participant.

[Insert Figure 3 about here]

CV dichotic listening

The procedure was the same as for Experiment 1.

\section{EmoDL long}

Participants heard two stimuli simultaneously in each dichotic trial, one in the left ear and one in the right ear. Participants were informed that would be presented with two words spoken in two different emotional tones simultaneously in each trial, and were instructed to report back the emotional tone that sounded clearer or captured more of their 
attention. They were instructed to focus on the emotional tone of the speaker, and to ensure that attention was centred and allocated equally to each emotional tone. Participants were given a response sheet which depicted the four emotions in line drawn facial expressions and were told to focus their attention on the sheet throughout the task. They were asked to give their answers by pointing to the image depicting the emotion and to verbally report the emotional tone to the experimenter. The experimenter entered the response using keyboard which triggered the next trial. A rest period was offered between each block.

EmoDL short

The procedure was identical to the long version.

\section{Results}

Chimeric faces 1.0

Right handers $(M=-15.32, S D=23.85)$ were found to be lateralised on the task, displaying an overall bias towards reporting the emotion displayed on the left side of the face, $t(70)-5.41, p<.001$. Non-right handers $(M=-4.54, S D=26.21)$ were not lateralised on the task, $t(67)=-1.43, p=.158$. It was found that right handed participants, on average, had a stronger bias to the left hemiface compared to non-right handed participants, $t(137)$ $=-2.54, p=.006$ (one-tailed), $d=0.43$.

Four right handers (5.6\%) and six non-right handers (8.8\%) had LIs of 0 . Out of participants with a directional bias, $74.6 \%$ (50/67), of right handers, 95\% CI [63.1\%, 83.5\%], and 59.7\% (37/62) of non-right handers, 95\% CI [47.3\%, 71.0\%], had leftward 
biases and differed significantly from one another, $z=1.81, p=.035$ (one-tailed), however, $95 \% \mathrm{CI}$ of the difference $(14.9 \%)$ overlapped with zero $[-30.2 \%,+1.2 \%]$.

Chimeric faces 2.0

As with the previous chimeric face task, right handers $(M=-21.81, S D=34.93)$, were found to be lateralised on the task, displaying an overall bias towards the chimera with the target emotion displayed on the left side, $t(199)=-8.83, p<.001$. Non-right handers $(M=-3.34, S D=42.62)$ were, again, not lateralised on the task, $t(145)=-0.95$, $p=.346$. It was found that right handed participants, on average, had a stronger bias to the left side of the face compared to non-right handed participants, $t(274.01)=-4.29, p<$ .001 (one-tailed), $\mathrm{d}=0.47$.

Ten right handers $(5.0 \%)$ and 8 non-right handers $(5.5 \%)$ had LIs of 0 . Out of participants with a directional bias, 72.6\% (138/190) of right handers, 95\% CI [65.9\%, 78.5\%], and 56.5\% (78/138) non-right handers, 95\% CI [48.2\%, 64.5\%], had leftward biases and differed significantly from one another, $z=3.04, p=.001$ (one-tailed). The 95\% CI of difference $(-16.1 \%)$ did not overlap with zero [-26.3\%, $-5.7 \%]$.

Colourscales task

We found no evidence for a more robust left-sided bias in this sample of individuals using colourscales relative to greyscales. Right handers $(M=-16.05, S D=$ 39.94) were found to have a significant left side bias on the task, $t(261)=-6.50, p<.001$. Non-right handers $(M=-23.81, S D=40.07)$ were also found to have a significant left side bias, $t(188)=-8.17, p<.001$. As mean LIs for the right handed group were numerically smaller than those of the non-right handers, and thus opposite to our onetailed prediction, a t-test was not performed. 
Seventeen (6.5\%) right handers had LIs of 0, as did $12(6.4 \%)$ non-right handers. Of people with a directional bias, $66.1 \%$ of the right handers $(162 / 245), 95 \%$ CI [ $60.0 \%$, $71.8 \%]$, and $72.9 \%$ of the non-right handers (129/177), 95\% CI [65.9\%, 78.9\%], had leftward biases. As this goes against our predictions, no further analysis was performed.

CV dichotic listening

Both right handers $(M=+26.14, S D=27.84)$, and non-right handers $(M=+19.20$, $S D=33.04$ ), had significant right ear advantages on the task (right handers: $t(261)=$ 15.20, $p<.001$; non-right handers: $t(187)=7.97, p<.001)$. The mean REA was, on average, higher in right handed participants $t(359.26)=2.35, p=.010$ (one-tailed), $d=$ 0.23 .

Two participants (both non-right handers; $1 \%$ ) had no ear advantage (NEA; i.e. a LI of 0 ) in the task. Out of participants with a directional bias, $85.1 \%$ of right handers (223/262), 95\% CI [80.3\%, 88.9\%], and $78.5 \%$ of non-right handers (146/186), 95\% CI $[72.0 \%, 83.8 \%]$, had a REA. The proportion of participants with a REA was found to be higher in the right handed compared to non-right handed group, $z=1.81, p=.035$ (onetailed), however, the $95 \%$ CI of the difference (-6.6\%) overlapped with zero $[-14.1 \%$, $0.5 \%]$.

\section{EmoDL long}

Both handedness groups had a small but significant overall bias towards the left ear (right handers: $t(72)=-2.41, p=.019$, non-right handers: $t(67)=-2.59, p=.012)$. Mean LIs for the right handers $(-8.96, S D=31.77)$ and non-right handers $(-10.38, S D=33.08)$ were numerically in the unpredicted direction and no statistical tests were performed. When investigating the percentages of right handers and non-right handers with a LEA, it was 
found that $63.0 \%(46 / 73)$ of right handers, 95\% CI [51.5\%, 73.2\%], and 63.2\% (43/68) of non-right handers, 95\% CI [51.4\%, 73.7\%], had a LEA, which again is numerically in the unpredicted direction and no statistical tests were performed.

EmoDL short

As predicted, both right handers $(M=-14.07, S D=30.48)$ and non-right handers $(-8.41, S D=30.97)$ had an overall significant bias towards the left ear, right handers: $t(199)=-6.53, p<.001$; non-right handers: $t(145)=-3.28, p=.001$. Right handers were found to have a higher average LI score compared to non-right handers, $t(344)=-1.69, p$ $=.046$ (one-tailed), $d=0.18$. When comparing percentages of individuals with a left ear advantage, $73.5 \%(147 / 200)$ of right handers, 95\% CI [67.0\%, 79.1\%], and $63.4 \%$ (92/145) of non-right handers, $95 \%$ CI [55.4\%, 70.8\%], had a bias towards the left ear, and this difference was found to be significantly decreased in the non-right handed sample, $z=1.20, p=.023$ (one-tailed). The $95 \% \mathrm{CI}$ of the difference $(-10.1 \%)$ did not overlap with zero $[-19.9 \%,-0.2 \%]$.

\section{Discussion}

The most unequivocal finding of this study, coupled with the results of Experiment 1, is that our attentional task (greyscales/colourscales) is similarly left biased in our right handed and non-right handed samples. For CV dichotic listening, the results are more mixed. Although differences in the predicted direction were obtained in both studies for central tendency and for proportions, the proportional differences were not significant in Experiment 1. The clearest differences in proportions were obtained for both of our chimeric faces procedures, where roughly $15 \%$ more of right handers were left biased relative to the non-right handers. EmoDL short version came close, with a significant $10 \%$ reduction in the proportion of non-right handers relative to right handers 
with a LEA. The mean LI was also significantly lower in the non-right handers, as predicted.

At this stage in the experiments, we decided to gather data from other laboratories who used the same, or similar, tasks in right handed and non-right handed groups, to perform meta-analyses of the proportions of people with typical and atypical lateral biases. There have been a small number of related meta-analyses, one on line bisection (Jewel \& McCourt, 2000) and the other on visual free viewing biases (including chimeric faces and greyscales; Voyer, Voyer, \& Tramonte, 2012). They both find small effects of handedness in the predicted direction, but are of central tendency and therefore could not be used to explore our frequency-related predictions.

To examine the likely best estimates for proportions, we have updated our previous meta-analysis on the REA in verbal dichotic listening (Carey \& Johnstone, 2014; Westerhausen \& Kompus, 2018). As mentioned earlier, there is a small literature on handedness and chimeric face bias which provides raw frequency data, so it too could be meta-analysed. In addition to the more recent data provided by Innes et al., 2015, we also requested frequency data for the greyscales task from the still active authors who had used it. Almost all of them were willing and able to provide us with frequency data on side biases. Similarly, we managed to obtain or identify frequency data on emotional dichotic listening tasks from 21 other experiments that tested right handed participants. A small subset (6) of these also tested non-right handers.

\section{Experiment 3. Meta-analyses}

We conducted these meta-analyses using a random effects model implemented in the MetaXL software developed by Barendregt and colleagues, available as freeware 
from http://www.epigear.com/index_files/metaxl.html. As discussed in our previous set of meta analyses (Carey \& Johnstone, 2014), the prevalence approach used here is described in more detail in Barendregt, Doi, Lee, Norman, and Vos (2013). For each task, we first meta-analyse frequency data for right handers and non-right handers separately, reporting the best estimate of frequency of typical bias along with the $95 \%$ confidence intervals. We do so because more studies are available for the right handed participants, which allows for greater confidence in these estimates of side bias for this group. These frequency-based meta-analyses all appear in the supplementary materials along with the derived weights, with proportions of "typical" biases estimated for both groups for every study. We also provide Doi plots (Furuya-Kanamori, Barendregt, \& Doi, 2018) for estimating publication bias as an Appendix (which do suggest some publication bias for colourscales/greyscales and chimeric faces, in particular). Unfortunately, to compare frequencies in right handers and non-right handers, we can only include those rare experiments that included both handedness groups. Unsurprisingly, these smaller analyses reveal considerable heterogeneity, as assessed by the obtained Q and $\mathrm{I}^{2}$ statistics. For three of our tasks, the results appear in Figure 4.

Literature searches in Pubmed revealed 308 sources when "dichotic listening" was searched for (1 May 2019) in the previous five-year period (chosen because our metaanalysis from Carey \& Johnstone, 2014 covered earlier papers). Our focus at this stage was to identify any additional large study or studies that included right handed and nonright handed participants. We also contacted colleagues known to use syllabic dichotic listening enquiring about additional unpublished large datasets that included non-right handers. For emotional dichotic listening, we searched on the conjunction of emotion and dichotic listening (no time restriction) yielding 23 potential sources. In addition, we used cited reference searches on Bryden and MacRae (1989), Erhan et al. (1988), and 
Grimshaw et al. (2003). Finally, a Pubmed search on "greyscales" revealed 34 items. We also used cited reference searched on Mattingley et al. (1994), and Nicholls et al. (1999).

In the supplementary materials we provide the raw frequency data for each study, as well as details on the weightings of each experiment in calculation of the overall effect and $95 \%$ CIs. As in our previous report, we used the same weighting to calculate frequency estimates for typical bias in both right handed and non-right handed samples.

\section{Chimeric faces}

In right handed participants, the overall bias to the left side of the stimulus was $76 \%, 95 \%$ CI [71\%, 81\%]. In non-right handers, this figure is $57 \%, 95 \%$ CI [ $51 \%, 64 \%]$. The omnibus analysis provides a typical bias rate ratio of $1.23,95 \%$ CI $[1.09,1.38]$, suggesting a reduced left sided bias in the non-right handers, as expected. The relevant forest plot appears as Figure 4A.

[Insert Figure 4 about here]

\section{Verbal dichotic listening}

These analyses build on our rather exhaustive literature search for Carey and Johnstone (2014). Westerhausen and Kompus (2018) added to our analyses with additional studies and removed all the visual half field experiments to concentrate on dichotic listening studies. We have added to their data with additional unpublished frequency data from the Bergen IDichotic database (Bless et al., 2013; 2015) as well as additional experiments that have been published or have come to our attention. In this analysis, unlike our previous effort (Carey \& Johnstone, 2014), we have excluded participants with numerically equal scores (NEA) for the two ears, to only include 
participants with ear biases. Analysis of REA frequencies in right handers from our 67 samples suggests an $81 \%$ prevalence of a REA, 95\% CI [79\%, 84\%]. In the 57 non-right handed samples, REA prevalence is $67 \%$, 95\% CI [64\%, 70\%]. The omnibus analysis reveals a typical bias rate ratio of $1.19,95 \%$ CI $[1.15,1.24]$, suggesting increased frequency of a REA in right handers relative to non-right handers. The relevant forest plot figure is available in the supplementary materials.

\section{Emotional dichotic listening}

We identified 21 studies where we could extract frequency data from published reports and personal communications with authors. Right handed samples as a whole are $70 \%$ left ear biased, 95\% CI [65\%, 74\%]. The smaller number (6) of studies with nonright handed participants available suggest that $63 \%$ are left ear biased, 95\% CI [57\%, 70\%]. The relative rates of left ear bias in the two groups were compared directly in Figure 4B. The rate ratio is $1.11,95 \%$ CI $[.96,1.29]$. As the $95 \%$ CI overlap with 1.0 , we cannot conclude a significant $9 \%$ reduction in typical bias is in the non-right handed sample.

\section{Greyscales/colourscales}

Data from the 29 individuals tested on both of our tasks is used in the greyscale estimate (Experiment 1) only. These data also suggest that there is no substantive difference between right handers and non-right handers in terms of what we describe here as the breadth of left-sided bias (although we must acknowledge that almost all data from non-right handed participants comes from our two samples). In right handed samples, the frequency of left-sided bias is $74 \%, 95 \%$ CI [70\%, 78\%]. In the non-right handed samples, $73 \%$ left-sided bias was found, 95\% CI [69\%, 77\%]. The omnibus analysis, which only uses those studies which include right handers and non-right handers, provides a relative 
rate ratio of 0.97 , suggesting slightly more frequent left bias in the non-right handers (opposite to our one-tailed prediction). The 95\% CI [.90, 1.03], overlap with one, suggesting no difference in left-sided bias in non-right handers compared with right handers. The forest plot appears as Figure 4C.

\section{General discussion}

Two of our asymmetry tasks provide support for the hypothesized reduced frequency of typical bias in non-right handed participant groups: chimeric faces and verbal dichotic listening. The effects are not as dramatic as the $15-20 \%$ difference suggested by Wada test data and other more direct measures such as neuroimaging. This reduced sensitivity is not particularly unexpected, given intact interhemispheric communication (c.f. Springer \& Gazzaniga, 1975), attentional biases in dichotic listening, noise introduced by subtle differences in hearing between ears, and so on (Graves, 1983; Satz, 1977).

The evidence for emotional listening is somewhat less convincing. Although numerically $9 \%$ fewer non-right handers are left eared on this task relative to the right handers, as predicted, the confidence intervals on the relative rate ratios just overlap with one. This result suggests that we cannot conclude that emotional dichotic listening is dependent less often on the right hemisphere in non-right handers. To date we could only meta-analyse 8 datasets for the depth of left ear advantages in right handers and non-right handers on this type of task. The more convincing samples (in terms of the numbers of non-right handers tested) suggest; 1. greater frequency of LEA in non-right handers (two studies: Bryden et al., 1991; McNeeley \& Netley, 1998); 2. greater frequency of LEAs in right handers (Grimshaw, 1998; this paper short version) and 3. no difference between the groups (this paper, long version). Of course, our short version of emotional dichotic 
listening, which was constructed to remove stimulus dominance effects, provides a $10 \%$ difference in the predicted direction, and was created and administered in our own laboratory, which is likely to bias us to some degree towards not giving up on the idea of a proportional decrease in non-right handed samples.

The lack of difference between the two groups is clearest for the greyscales/colourscales task. The three present experiments, collectively, suggest that the left-sided bias frequency on greyscales/colourscales does not differ between right handed and non-right handed samples, despite its' rather impressive breadth $(\sim 75 \%)$. These data suggest that whatever function (or functions) that greyscales and colourscales performance depends on, is not complementary in nature to the typically obtained asymmetries in these handedness groups on speech and language functions (Carey \& Johnstone, 2014). Our working hypothesis is that some right hemispheric functions are not yoked to language in a type of complementary hemispheric fashion (see Bryden, 1990; Harms \& Elias, 2014; Whitehouse \& Bishop, 2009; reviewed recently by Badzakova-Trajkov, Corballis, \& Häberling, 2016) that is often assumed in the handedness and cerebral asymmetries literature. However, we must first eliminate noncerebral models that could account for a left-sided visual bias of the breadth seen in these two experiments, as well as in our meta-analysis of much of the greyscales literature in Experiment 3.

The most obvious explanation that does not depend on a right-hemisphere specialization account is the attentional and/or scanning bias resulting from left to right reading in English. A life history of reading in a particular direction may lead to a scanning to or attentional preference for the start direction (see Chung, Liu, \& Hsiao, 2017, for evidence for very acute effects of reading on greyscales for Chinese people who can read in both directions). This concern has repeatedly been expressed for other 
behavioural asymmetries, including line bisection and face processing (e.g. Chokron, Bernard, \& Imbert, 1997; Sakhuja, Gupta, Singh, \& Vaid, 1996; Vaid \& Singh, 1989). Fortunately, this reading direction bias hypothesis for greyscales/colourscales, can be addressed. The most direct way of doing so is to measure the proportion who show leftsided biases on greyscales in people who normally read right to left. Four samples of such data exist (albeit with right handed participants only).

Nicholls and Roberts (2002) compared 20 English readers with 20 Hebrewreading Israeli tourists on the greyscales task and a line bisection task. Although the mean greyscale LIs were numerically lower in the Hebrew readers, they were not significantly less left biased, on average, compared to the English readers. We have calculated the proportions showing the left bias in both samples from individual participant data kindly provided by Nicholls. The percentage of individuals with a left-side bias was not significantly greater in English reading participants (75\%) than that found in Hebrew reading participants $(70 \%), z=.35, p=.726$, and $95 \% \mathrm{CI}$ of difference $(5 \%)$ overlaps with zero $[-3.09 \%,+21.8 \%]$.

However, three later studies with larger samples do find that right to left readers show reduced breath in the left bias for greyscales. Friedrich and Elias (2014) gave the task to 54 English readers and 43 Hebrew readers. If individuals with no bias are removed, the typical bias was found in $81 \%$ of the 53 English readers. In the Hebrew readers, the typical bias was present in $60 \%$ of the 42 people. This difference has $95 \%$ CIs that do not overlap with zero $[-39 \%,-3 \%]$, suggesting that there is a reduced left sided bias in participants who read in a right to left direction. R. Tomer (personal communication, January 08,2018 ) and her colleagues provided us with individual participant data from an unpublished experiment and from Zozulinsky et al. (2014). Both studies suggest reduced breadth of the left-side bias in Hebrew readers. In the unpublished study, $57 \%$ of 
participants, 95\% CI [47.3\%, 66.5\%], showed a left-sided bias. In Zozulinsky et al. (2014), 53\% of participants showed a left sided bias, 95\% CI [45.8\%, 59.6\%].

Nevertheless, reading direction is unlikely to completely account for the bias in English reading participants, at least on this evidence, as the majority of right to left readers are not right biased on this task. This point has been made several times in other literatures on left sided biases and reading direction (Fagard \& Dahmen, 2003; Nicholls \& Roberts, 2002; Rinaldi, Di Luca, Henik, \& Girelli, 2014; Vaid \& Singh, 1989). Nevertheless, most Hebrew readers are fluent English readers as well and their number system works from left to right, as pointed out to us by Rachel Tomer. It may be worth testing monolinguals who use a right-to-left reading script such as Arabic, Kurdish, Farsi or Urdu with colourscales or greyscales.

Of course, the left ear bias for emotional prosody cannot be explained away by a mechanism such as reading direction. Neuroimaging studies of prosody have focused exclusively on right-handed participants, and so cannot to date speak to a potential difference between right handers and non-right handers. We are currently working on quantifying the depth and breadth of prosody asymmetry measured by fMRI in both rightand non-right handed individuals with known cerebral dominance for language. These new data might speak to difference in prosody asymmetry between handedness groups in the near future.

In contrast to the research on emotional prosody using fMRI, attentional functions have, recently, been studied in right and non-right handed groups. One puzzle about the current greyscales/colourscales findings is that the results differ from what would be expected given a recent neuroimaging study by Cai, Van der Haegen, and Brysbaert (2013). Their study provides very strong support for complementary hemispheric specialization of language and attentional functions, in non-right handers, at least. Cai et 
al. (2013) used an fMRI-friendly variant of the landmark task to measure attentional asymmetry, rather than the greyscales task. It requires participants to make judgments about pre-bisected horizontal lines, modelled after line bisection used in studies of hemispatial neglect. They found that all 15 non-right handed participants with right hemispheric language dominance identified from a previous experiment (Van der Haegen, Cai, Seurinck, \& Brysbaert, 2011) were left hemispheric for attention. Similarly, 15 of the 16 non-right handers who were left lateralized for language were right lateralized on the landmark task. However, for this study, a cut-off $\mathrm{LI} \geq 0.5$ or $\leq-0.45$ was used to exclude participants who were classified as bilateral on their verbal fluency task.

Badzakova-Trajkov, Häberling, Roberts, and Corballis (2010) also contrasted landmark and verbal fluency in a sample of 48 non-right handers and 107 right handers. They provide scatterplots of individual LIs for their right handers and non-right handers for a landmark task, verbal fluency, and face task. Zago et al. (2016) kindly provided us with data from a similar fMRI experiment including landmark and verbal fluency in a sample of 142 right handers and 151 non-right handers. The data from these two studies are remarkably clear: right handers and non-right handers differ in the expected direction on the proportion of people who are left lateralized for verbal fluency (BadzakovaTrajkov et al. 2010: $96 \%$ versus $81 \%$, 95\% CIs on the difference do not overlap zero; Zago et al. 2016: $94 \%$ versus $83 \%, 95 \%$ CIs on the difference do not overlap zero). With that result in mind, the crucial contrast becomes the breadth of right hemispheric dominance in the same participants. The proportions of participants with negative LIs (i.e. right hemispheric dominance) for the landmark task are virtually identical in the two studies (Badzakova-Trajkov et al. 2010: right handed 79.4\% versus non-right handed 79.2\%, 95\% CIs on the difference overlap with zero; Zago et al. 2016: right handed 
$81.7 \% \%$ versus non-right handed $78.8 \%, 95 \%$ CIs on the difference overlap with zero). In other words, right handers and non-right handers, assessed for both language and attentional dominance differ in the predicted direction for language typicality, but are nearly identical for right hemispheric attentional dominance.

Of course, we do not know whether or not any underlying mechanisms driving greyscale left-sided biases are shared with whatever participants "use" when they perform the landmark task in the scanner, but the Badzakova-Trajkov et al. (2010) and Zago et al. (2016) neuroimaging results are certainly consistent with our suggestion here that some attentional functions do not differ in breadth in right handers and non-right handers, and are therefore unlikely candidates for complementary hemispheric specialization with speech and language.

Behavioural asymmetry estimates might lack sufficient sensitivity to provide accurate proportions of typical and atypical cerebral dominance for any lateralized function, let alone right hemispheric attention. Nevertheless, our meta-analyses on chimeric face processing and verbal dichotic listening are at the very least suggestive; a reduced prevalence of left side bias for chimeric faces in the non-right handers of nearly $20 \%$, and of the right ear bias for verbal material of approximately $15 \%$. It may be a coincidence, but language and face processing are the only two functional domains that are currently (and explicitly) hypothesised to be complementary to one another (Behrmann \& Plaut, 2015; Centanni et al., 2018; Dehaene, Cohen, Morais, \& Kolinsky, 2015; Plautt \& Behrmann, 2011).

Sensitivity of these behavioural tests is, obviously a concern. In our most powered analyses, given our own sample sizes, the group differences in CV dichotic listening are not large, for example only a 7-9\% increase in prevalence of REAs in the right handers. In the multi-study meta-analyses (Carey \& Johnstone, 2014) this difference in 
considerably larger: about $16 \%$. These data, as a whole, suggest that, despite their indirect assessment of the underlying asymmetry, that verbal dichotic listening tests can capture at least some of the difference between right handed and non-right handed in terms of speech and language dependence on the left hemisphere.

By contrast, neuroimaging estimates of typical and atypical dominance tend to produce more robust proportional differences (for language and speech asymmetries at least). Large sample neuroimaging studies of right handers and non-right handers are relatively few (Allendorfer et al., 2016; Häberling, Corballis, \& Corballis, 2016; Króliczak, Piper, \& Frey, 2016; Mazoyer et al., 2016; Tzourio-Mazoyer et al., 2015; Van der Haegen et al., 2011). They are quite expensive to run, given the costs of neuroimaging as well as the time it takes to recruit large numbers of non-right handers, who are relatively rare (for a review of the unfortunately exclusion of non-right handers from psychology and neuroscience, see Willems, Van der Haegen, Fisher, \& Francks, 2014). The length of single scanning sessions will also be limited by how long each participant is able to remain still (and perform adequately on the task at hand) in the scanner. A behavioural approach, we humbly suggest, could be a useful tool in the longer-term goal of characterizing which cerebral asymmetries are related to each other in a complementary fashion, and which ones are statistically independent.

A recent series of replications of classic visual half field studies reveals quite consistent rightward lateralisation for face and attentional processing and leftward lateralisation for lexical decision, in right handed samples (Brederoo, Nieuwenstein, Cornelissen, \& Lorist, 2019). However, for data like ours, which compare asymmetries in right- and non-right handed groups, skew is a particular challenge. Combined with the relatively subtle difference in proportions of right handers and non-right handers who show typical dominance (at least for language), creating a taxonomy of related and 
unrelated cerebral asymmetries as a function of handedness will not be easy. Having said that, these tasks are easy to set up and administer. In fact, the kind of large numbers required for our proportional analyses lend themselves rather nicely to a multi-lab approach which for example, has been recently used to great effect in examining visual half field studies of lexical decision (Hausmann et al., 2019). We submit that behavioural psychology can contribute substantially to such taxonomic efforts, in ways that expensive, time constrained, brain scans cannot. 

Acknowledgements: We are extremely grateful to all the authors who provided us with LIs for their individual participants: Abdul Alzahrani, David Boles, Xiaohua Cao, Rodrigo Cardenas, Jiaqing Chen, Harry Chung, Michael Corballis, Lorin Elias, Michael English, Trista Friedrich, Gina Grimshaw, Melita Giummarra, Lauren Harris, Markus Hausmann, Bobby Innes, Michal Lavidor, Gemma Learmonth, Chenglin Li, Jason Mattingley, Mike Nicholls, Matthias Niemeier, Sebastian Ocklenburg, Ayelet Sapir, Mark Tant, Nicole Thomas, Rachel Tomer, and Laure Zago. Llewelyn Morris, Elfyn Roberts, David Robinson, and David McKiernan constructed the bespoke rear-projection short throw projector system used in Experiment 1. We are happy to share our colourscales stimuli and our emotional dichotic listening stimuli as executable scripts: interested parties please email e.karlsson@bangor.ac.uk or d.carey@ bangor.ac.uk.Emma Karlsson was supported by a Bangor University School of Psychology PhD Scholarship. Leah Johnstone was supported by a Bangor University 125 Anniversary Scholarship. This research has been supported in part by a Leverhulme Trust research grant (RPG-2019102) to D.P.C.

Disclosure of interest: The authors report no conflict of interest 


\section{References}

Allendorfer, J. B., Hernando, K. A., Hossain, S., Nenert, R., Holland, S. K., \& Szaflarski, J. P. (2016). Arcuate fasciculus asymmetry has a hand in language function but not handedness. Human Brain Mapping, 37(9), 3297-3309. doi:10.1002/hbm.23241

Alzahrani, A. D., \& Almuhammadi, M. A. (2013). Left ear advantages in detecting emotional tones using dichotic listening task in an Arabic sample. Laterality: Asymmetries of Body, Brain and Cognition, 18(6), 730-747. doi:10.1080/1357650X.2012.762373

Badzakova-Trajkov, G., Corballis, M. C., \& Häberling, I. S. (2016). Complementarity or independence of hemispheric specializations? A brief review. Neuropsychologia, 93B, 386-393. doi:10.1016/j.neuropsychologia.2015.12.018

Badzakova-Trajkov, G., Häberling, I. S., Roberts, R. P., \& Corballis, M. C. (2010). Cerebral asymmetries: Complementary and independent processes. PloS one, 5(3), e9682. doi:10.1371/journal.pone.0009682

Barendregt, J. J., Doi, S. A., Lee, Y. Y., Norman, R. E., \& Vos, T. (2013). Metaanalysis of prevalence. Journal of Epidemiology and Community Health, 67, 974-978. doi:10.1136/jech-2013-203104 
Behrmann, M., \& Plaut, D. C. (2015). A vision of graded hemispheric specialization. Annals of the New York Academy of Sciences, 1359(1), 30-46. doi:10.1111/nyas.12833

Bless, J. J., Westerhausen, R., Arciuli, J., Kompus, K., Gudmundsen, M., \& Hugdahl, K. (2013). "Right on all occasions?"-On the feasibility of laterality research using a smartphone dichotic listening application. Frontiers in Psychology, 4, 42. doi:10.3389/fpsyg.2013.00042

Bless, J. J., Westerhausen, R., Torkildsen, J. V. K., Gudmundsen, M., Kompus, K., \& Hugdahl, K. (2015). Laterality across languages: Results from a global dichotic listening study using a smartphone application. Laterality: Asymmetries of Body, Brain and Cognition, 20(4), 434-452. doi:10.1080/1357650X.2014.997245

Branch, C., Milner, B., \& Rasmussen, T. (1964). Intracarotid sodium amytal for the lateralization of cerebral speech dominance: Observations in 123 patients. Journal of Neurosurgery, 21(5), 399-405. doi:10.3171/jns.1964.21.5.0399

Brederoo, S. G., Nieuwenstein, M. R., Cornelissen, F. W., \& Lorist, M. M. (2019). Reproducibility of visual-field asymmetries: Nine replication studies investigating lateralization of visual information processing. Cortex, 111, 100126. doi:10.1016/j.cortex.2018.10.021 
Bryden, M. P. (1960). Tachistoscopic recognition of non-alphabetical material. Canadian Journal of Experimental Psychology, 14(2), 78-86. doi:10.1037/h0083169

Bryden, M. P. (1990). Choosing sides: The left and right of the normal brain. Canadian Psychology, 31, 297-309. doi:10.1037/h0078949

Bryden, M. P., Free, T., Gagné, S., \& Groff, P. (1991). Handedness effects in the detection of dichotically-presented words and emotions. Cortex, 27(2), 229-235. doi:10.1016/S0010-9452(13)80127-X

Bryden, M. P., Hécaen, H., \& DeAgostini, M. (1983). Patterns of cerebral organization. Brain and Language, 20(2), 249-262. doi:10.1016/0093-934X(83)90044-5

Bryden, M. P., \& MacRae, L. (1989). Dichotic laterality effects obtained with emotional words. Neuropsychiatry, Neuropsychology, \& Behavioral Neurology, 1(3), 171176.

Burt, D. M., \& Perrett, D. I. (1997). Perceptual asymmetries in judgements of facial attractiveness, age, gender, speech and expression. Neuropsychologia, 35(5), 685-693. doi:10.1016/S0028-3932(96)00111-X

Cai, Q., Van der Haegen, L., \& Brysbaert, M. (2013). Complementary hemispheric specialization for language production and visuospatial attention. Proceedings of 
the National Academy of Sciences, 110(4), E322-E330.

doi:10.1073/pnas.1212956110

Carey, D. P., \& Johnstone, L. T. (2014). Quantifying cerebral asymmetries for language in dextrals and adextrals with random-effects meta analysis. Frontiers in Psychology, 5, 1128. doi:10.3389/fpsyg.2014.01128

Centanni, T. M., Norton, E. S., Park, A., Beach, S. D., Halverson, K., Ozernov-Palchik, O., ... \& Gabrieli, J. D. (2018). Early development of letter specialization in left fusiform is associated with better word reading and smaller fusiform face area. Developmental Science, e12658. doi:10.1111/desc.12658

Chokron, S., Bernard, J. M., \& Imbert, M. (1997). Length representation in normal and neglect subjects with opposite reading habits studied through a line extension task. Cortex, 33(1), 47-64. doi:10.1016/S0010-9452(97)80004-4

Chung, H. K., Liu, J. Y., \& Hsiao, J. H. (2017). How does reading direction modulate perceptual asymmetry effects? The Quarterly Journal of Experimental Psychology, 70(8), 1559-1574. doi:10.1080/17470218.2016.1193549

David, A. S. (1989). Perceptual asymmetry for happy-sad chimeric faces: Effects of mood. Neuropsychologia, 27(10), 1289-1300. doi:10.1016/00283932(89)90041-9 
Dehaene, S., Cohen, L., Morais, J., \& Kolinsky, R. (2015). Illiterate to literate: behavioural and cerebral changes induced by reading acquisition. Nature Reviews Neuroscience, 16(4), 234-244. doi:10.1038/nrn3924

Dehaene, S., Pegado, F., Braga, L. W., Ventura, P., Nunes Filho, G., Jobert, A., ... \& Cohen, L. (2010). How learning to read changes the cortical networks for vision and language. Science, 330(6009), 1359-1364. doi:10.1126/science.1194140

Démuthová, S., \& Démuth, A. (2018). Handedness and the Preference of the Visual Field in Face Perception. European Scientific Journal, 14(6). doi:10.19044/esj.2018.c3p8

Donnot, J., \& Vauclair, J. (2007). Infant holding preferences in maternity hospitals: Testing the hypothesis of the lateralized perception of emotions. Developmental Neuropsychology, 32(3), 881-890. doi:10.1080/87565640701539774

Dronkers, N. F., \& Knight, R. T. (1989). Right-sided neglect in a left-hander: Evidence for reversed hemispheric specialization of attention capacity. Neuropsychologia, 27(5), 729-735. doi:10.1016/0028-3932(89)90118-8

Elias, L. J., Bryden, M. P., \& Bulman-Fleming, M. B. (1998). Footedness is a better predictor than is handedness of emotional lateralization. Neuropsychologia, 36(1), 37-43. doi:10.1016/S0028-3932(97)00107-3 
English, M. C., Maybery, M. T., \& Visser, T. A. (2015). Individuals with autistic-like traits show reduced lateralization on a greyscales task. Journal of Autism and Developmental Disorders, 45(10), 3390-3395. doi:10.1007/s10803-015-2493-7

Enriquez, P., \& Bernabeu, E. (2008). Hemispheric laterality and dissociative tendencies: Differences in emotional processing in a dichotic listening task. Consciousness and Cognition, 17(1), 267-275. doi:10.1016/j.concog.2007.06.001

Erhan, H., Borod, J. C., Tenke, C. E., \& Bruder, G. E. (1998). Identification of emotion in a dichotic listening task: event-related brain potential and behavioral findings. Brain and Cognition, 37(2), 286-307. doi:10.1006/brcg.1998.0984

Fagard, J., \& Dahmen, R. (2003). The effects of reading-writing direction on the asymmetry of space perception and directional tendencies: A comparison between French and Tunisian children. Laterality: Asymmetries of Body, Brain and Cognition, 8(1), 39-52. doi:10.1080/713754473

Friedrich, T. E., \& Elias, L. J. (2014). Behavioural asymmetries on the greyscales task: The influence of native reading direction. Culture and Brain, 2(2), 161-172. doi:10.1007/s40167-014-0019-3

Furuya-Kanamori, L., Barendregt, J. J., \& Doi, S. A. (2018). A new improved graphical and quantitative method for detecting bias in meta-analysis. International Journal of Evidence-based Healthcare, 16(4), 195-203. doi:10.1097/XEB.0000000000000141 
Gazzaniga, M. S., \& Sperry, R. W. (1967). Language after section of the cerebral commissures. Brain: A Journal of Neurology, 90(1), 131-148.

doi:10.1093/brain/90.1.131

Gilbert, C., \& Bakan, P. (1973). Visual asymmetry in perception of faces. Neuropsychologia, 11(3), 355-362. doi:10.1016/0028-3932(73)90049-3

Graves, R. (1983). Mouth asymmetry, dichotic ear advantage and tachistoscopic visual field advantage as measures of language lateralization. Neuropsychologia, 21(6), 641-649. doi:10.1016/0028-3932(83)90062-3

Grimshaw, G. M. (1998). Integration and interference in the cerebral hemispheres: Relations with hemispheric specialization. Brain and Cognition, 36(2), 108-127. doi:10.1006/brcg.1997.0949

Grimshaw, G. M., Kwasny, K. M., Covell, E., \& Johnson, R. A. (2003). The dynamic nature of language lateralization: effects of lexical and prosodic factors. Neuropsychologia, 41(8), 1008-1019. doi:10.1016/S0028-3932(02)00315-9

Grimshaw, G. M., McManus, I. C., \& Bryden, M. P. (1994). Controlling for stimulus dominance in dichotic listening tests: A modification of $\lambda$. Neuropsychology, 8(2), 278. doi:10.1037/0894-4105.8.2.278 
Häberling, I. S., Corballis, P. M., \& Corballis, M. C. (2016). Language, gesture, and handedness: Evidence for independent lateralized networks. Cortex, 82, 72-85. doi:10.1016/j.cortex.2016.06.003

Harms, V. L., \& Elias, L. J. (2014). Examination of complementarity in speech and emotional vocalization perception. Psychology, 5(08), 864-874. doi:10.4236/psych.2014.58098

Harris, L. J., Cárdenas, R. A., Stewart, N. D., \& Almerigi, J. B. (2019). Are only infants held more often on the left? If so, why? Testing the attention-emotion hypothesis with an infant, a vase, and two chimeric tests, one "emotional," one not. Laterality: Asymmetries of Body, Brain and Cognition, 24(1), 65-97. doi:10.1080/1357650X.2018.1475482

Hausmann, M., Brysbaert, M., van der Haegen, L., Lewald, J., Specht, K., Hirnstein, M., ... \& Roch, M. (2019). Language lateralisation measured across linguistic and national boundaries. Cortex, 111, 134-147. doi:10.1016/j.cortex.2018.10.020

Hécaen, H., \& Sauguet, J. (1971). Cerebral dominance in left-handed subjects. Cortex, 7(1), 19-48. doi:10.1016/S0010-9452(71)80020-5

Heller, W., \& Levy, J. (1981). Perception and expression of emotion in right-handers and left-handers. Neuropsychologia, 19(2), 263-272. doi:10.1016/00283932(81)90110-X 
Heron, W. (1957). Perception as a function of retinal locus and attention. The American Journal of Psychology, 70(1), 38-48. doi:10.2307/1419227

Hugdahl, K., \& Andersson, L. (1986). The "forced-attention paradigm" in dichotic listening to CV-syllables: a comparison between adults and children. Cortex, 22(3), 417-432. doi:10.1016/S0010-9452(86)80005-3

Hugdahl, K., \& Franzon, M. (1985). Visual half-field presentations of incongruent color-words reveal mirror-reversal of language lateralization in dextral and sinistral subjects. Cortex, 21(3), 359-374. doi:10.1016/S0010-9452(85)80002-2

Hugdahl, K., Westerhausen, R., Alho, K., Medvedev, S., Laine, M., \& Hämäläinen, H. (2009). Attention and cognitive control: unfolding the dichotic listening story. Scandinavian Journal of Psychology, 50(1), 11-22. doi:10.1111/j.14679450.2008.00676.x

Hughlings Jackson, J. (1879). On affections of speech from disease of the brain. Brain, 2, 203-222. doi:10.1093/brain/2.2.203

Innes, B. R., Burt, D. M., Birch, Y. K., \& Hausmann, M. (2016). A leftward bias however you look at it: Revisiting the emotional chimeric face task as a tool for measuring emotion lateralization. Laterality: Asymmetries of Body, Brain and Cognition, 21(4-6), 643-661. doi:10.1080/1357650X.2015.1117095 
Isaacs, K. L., Barr, W. B., Nelson, P. K., \& Devinsky, O. (2006). Degree of handedness and cerebral dominance. Neurology, 66(12), 1855-1858. doi:10.1212/01.wnl.0000219623.28769.74

Jewell, G., \& McCourt, M. E. (2000). Pseudoneglect: a review and meta-analysis of performance factors in line bisection tasks. Neuropsychologia, 38(1), 93-110. doi:10.1016/S0028-3932(99)00045-7

Kimura, D. (1983). Speech representation in an unbiased sample of left-handers. Human Neurobiology, 2(3), 147-154.

Knecht, S., Dräger, B., Deppe, M., Bobe, L., Lohmann, H., Flöel, A., ... \& Henningsen, H. (2000). Handedness and hemispheric language dominance in healthy humans. Brain, 123(12), 2512-2518. doi:10.1093/brain/123.12.2512

Króliczak, G., Piper, B. J., \& Frey, S. H. (2016). Specialization of the left supramarginal gyrus for hand-independent praxis representation is not related to hand dominance. Neuropsychologia, 93, 501-512. doi:10.1016/j.neuropsychologia.2016.03.023

Levy, J., Heller, W., Banich, M. T., \& Burton, L. A. (1983). Asymmetry of perception in free viewing of chimeric faces. Brain and Cognition, 2(4), 404-419. doi:10.1016/0278-2626(83)90021-0 
Li, C., Li, Q., Wang, J., \& Cao, X. (2018). Left-side bias is observed in sequential matching paradigm for face processing. Frontiers in Psychology, 9, 2005. doi:10.3389/fpsyg.2018.02005

Mattingley, J. B., Bradshaw, J. L., Nettleton, N. C., \& Bradshaw, J. A. (1994). Can task specific perceptual bias be distinguished from unilateral neglect? Neuropsychologia, 32(7), 805-817. doi:10.1016/0028-3932(94)90019-1

Mazoyer, B., Mellet, E., Perchey, G., Zago, L., Crivello, F., Jobard, G., ... \& Joliot, M. (2016). BIL\&GIN: A neuroimaging, cognitive, behavioral, and genetic database for the study of human brain lateralization. NeuroImage, 124, 1225-1231. doi:10.1016/j.neuroimage.2015.02.071

McNeely, H., \& Netley, C. (1998). Right hemisphere lateralization of emotional prosody recognition predicts introverted personality in left handers. Brain and Cognition, 37(1), 51-54.

McNeely, H. E., \& Parlow, S. E. (2001). Complementarity of linguistic and prosodic processes in the intact brain. Brain and Language, 79(3), 473-481. doi:10.1006/brln.2001.2502

Meyer, M., Alter, K., Friederici, A. D., Lohmann, G., \& von Cramon, D. Y. (2002). FMRI reveals brain regions mediating slow prosodic modulations in spoken sentences. Human Brain Mapping, 17(2), 73-88. doi:10.1002/hbm.10042 
Mishkin, M., \& Forgays, D. G. (1952). Word recognition as a function of retinal locus. Journal of Experimental Psychology, 43(1), 43-48. doi:10.1037/h0061361

Newcombe, F., \& Ratcliff, G. (1973). Handedness, speech lateralization and ability. Neuropsychologia, 11, 399-407. doi:10.1016/0028-3932(73)90026-2

Nicholls, M. E. R., Bradshaw, J. L., \& Mattingley, J. B. (1999). Free viewing perceptual asymmetries for the judgement of brightness, numerosity and size. Neuropsychologia, 37, 307-314, doi:10.1016/0028-3932(98)00074-8.

Nicholls, M. E. R., \& Roberts, G. R. (2002). Can free-viewing perceptual asymmetries be explained by scanning, pre-motor or attentional biases? Cortex, 38(2), 113136. doi:10.1016/S0010-9452(08)70645-2

Padovani, A., Pantano, P., Frontoni, M., Iacoboni, M., Di Piero, V., \& Lenzi, G. L. (1992). Reversed laterality of cerebral functions in a non-right-hander: Neuropsychological and spect findings in a case of 'atypical' dominance. Neuropsychologia, 30(1), 81-89. doi:10.1016/0028-3932(92)90016-F

Paulmann, S. (2016). The neurocognition of prosody. In Hickok, G., Small, S. (Eds.), Neurobiology of language (pp. 1109-1120). Cambridge, MA, US: Academic Press. 
Plaut, D. C., \& Behrmann, M. (2011). Complementary neural representations for faces and words: A computational exploration. Cognitive Neuropsychology, 28(3-4), 251-275. doi:10.1080/02643294.2011.609812

Rasmussen, T., \& Milner, B. (1977). The role of early left-brain injury in determining lateralization of cerebral speech functions. Annals of the New York Academy of Sciences, 299(1), 355-369. doi:10.1111/j.1749-6632.1977.tb41921.x

Rinaldi, L., Di Luca, S., Henik, A., \& Girelli, L. (2014). Reading direction shifts visuospatial attention: An interactive account of attentional biases. Acta Psychologica, 151, 98-105. doi:10.1016/j.actpsy.2014.05.018

Ross, E. D. (1981). The aprosodias: Functional-anatomic organization of the affective components of language in the right hemisphere. Archives of Neurology, 38(9), 561-569. doi:10.1001/archneur.1981.00510090055006

Roszkowski, M. J., \& Snelbecker, G. E. (1982). Temporal stability and predictive validity of self-assessed hand preference with first and second graders. Brain and Cognition, 1(4), 405-409. doi:10.1016/0278-2626(82)90025-2

Sakhuja, T., Gupta, G. C., Singh, M., \& Vaid, J. (1996). Reading habits affect asymmetries in facial affect judgments: A replication. Brain and Cognition, $32(2), 162-165$. 
Sammler, D., Grosbras, M. H., Anwander, A., Bestelmeyer, P. E., \& Belin, P. (2015). Dorsal and ventral pathways for prosody. Current Biology, 25(23), 3079-3085. doi:10.1016/j.cub.2015.10.009

Satz, P. (1977). Laterality tests: An inferential problem. Cortex, 13(2), 208-212. doi:10.1016/S0010-9452(77)80010-5

Shipley-Brown, F., Dingwall, W. O., Berlin, C. I., Yeni-Komshian, G., \& GordonSalant, S. (1988). Hemispheric processing of affective and linguistic intonation contours in normal subjects. Brain and Language, 33(1), 16-26. doi:10.1016/0093-934X(88)90051-X

Springer, S. P., \& Gazzaniga, M. S. (1975). Dichotic testing of partial and complete split brain subjects. Neuropsychologia, 13(3), 341-346. doi:10.1016/00283932(75)90011-1

Steenhuis, R. E., \& Bryden, M. P. (1989). Different dimensions of hand preference that relate to skilled and unskilled activities. Cortex, 25, 289-304. doi:10.1016/S0010-9452(89)80044-9

Tant, M. L. M., Kuks, J. B. M., Kooijman, A. C., Cornelissen, F. W., \& Brouwer, W. H. (2002). Grey scales uncover similar attentional effects in homonymous hemianopia and visual hemi-neglect. Neuropsychologia, 40(8), 1474-1481. doi:10.1016/S0028-3932(01)00197-X 
Thomas, N. A., \& Elias, L. J. (2012). Perceptual asymmetries in greyscales: Objectbased versus space-based influences. Cortex, 48(5), 553-562. doi:10.1016/j.cortex.2010.11.015

Tomer, R., Slagter, H. A., Christian, B. T., Fox, A. S., King, C. R., Murali, D., \& Davidson, R. J. (2012). Dopamine asymmetries predict orienting bias in healthy individuals. Cerebral Cortex, 23(12), 2899-2904. doi:10.1093/cercor/bhs277

Turnbull IV, O. H., \& Bryson, H. E. (2001). The leftward cradling bias and hemispheric asymmetry for speech prosody. Laterality: Asymmetries of Body, Brain and Cognition, 6(1), 21-28. doi:10.1080/713754394

Tzourio-Mazoyer, N., Marie, D., Zago, L., Jobard, G., Perchey, G., Leroux, G., ... \& Mazoyer, B. (2015). Heschl's gyrification pattern is related to speech-listening hemispheric lateralization: FMRI investigation in 281 healthy volunteers. Brain Structure and Function, 220(3), 1585-1599. doi:10.1007/s00429-014-0746-4

Vaid, J., \& Singh, M. (1989). Asymmetries in the perception of facial affect: Is there an influence of reading habits. Neuropsychologia, 27, 1277-1287. doi:10.1016/0028-3932(89)90040-7

Van der Haegen, L., Cai, Q., Seurinck, R., \& Brysbaert, M. (2011). Further fMRI validation of the visual half field technique as an indicator of language laterality: A large-group analysis. Neuropsychologia, 49(10), 2879-2888. doi:10.1016/j.neuropsychologia.2011.06.014 
Van Lancker, D., \& Sidtis, J. J. (1992). The identification of affective-prosodic stimuli by left-and right-hemisphere-damaged subjects: all errors are not created equal. Journal of Speech, Language, and Hearing Research, 35(5), 963-970. doi:10.1044/jshr.3505.963

Voyer, D., Bowes, A., \& Soraggi, M. (2009). Response procedure and laterality effects in emotion recognition: Implications for models of dichotic listening. Neuropsychologia, 47(1), 23-29. doi:10.1016/j.neuropsychologia.2008.08.022

Voyer, D., Russell, A., \& McKenna, J. (2002). On the reliability of laterality effects in a dichotic emotion recognition task. Journal of Clinical and Experimental Neuropsychology, 24(5), 605-614. doi:10.1076/jcen.24.5.605.1007

Voyer, S. D., \& Voyer, D. (2015). Laterality, spatial abilities, and accident proneness. Journal of Clinical and Experimental Neuropsychology, 37(1), 27-36. doi:10.1080/13803395.2014.985191

Voyer, D., Voyer, S. D., \& Tramonte, L. (2012). Free-viewing laterality tasks: A multilevel meta-analysis. Neuropsychology, 26(5), 551. doi:10.1037/a0028631

Westerhausen, R., \& Kompus, K. (2018). How to get a left-ear advantage: A technical review of assessing brain asymmetry with dichotic listening. Scandinavian Journal of Psychology, 59(1), 66-73. doi:10.1111/sjop.12408 
Whitehouse, A. J., \& Bishop, D. V. (2009). Hemispheric division of function is the result of independent probabilistic biases. Neuropsychologia, 47(8), 1938-1943. doi:10.1016/j.neuropsychologia.2009.03.005

Willems, R. M., Van der Haegen, L., Fisher, S. E., \& Francks, C. (2014). On the other hand: Including left-handers in cognitive neuroscience and neurogenetics. Nature Reviews Neuroscience, 15, 193-201. doi:10.1038/nrn3679

Witteman, J., van IJzendoorn, M. H., van de Velde, D., van Heuven, V. J., \& Schiller, N. O. (2011). The nature of hemispheric specialization for linguistic and emotional prosodic perception: a meta-analysis of the lesion literature. Neuropsychologia, 49(13), 3722-3738. doi:10.1016/j.neuropsychologia.2011.09.028

Zago, L., Petit, L., Mellet, E., Jobard, G., Crivello, F., Joliot, M., ... \& TzourioMazoyer, N. (2016). The association between hemispheric specialization for language production and for spatial attention depends on left-hand preference strength. Neuropsychologia, 93b, 394-406. doi:10.1016/j.neuropsychologia.2015.11.018

Zozulinsky, P., Greenbaum, L., Brande-Eilat, N., Braun, Y., Shalev, I., \& Tomer, R. (2014). Dopamine system genes are associated with orienting bias among healthy individuals. Neuropsychologia, 62, 48-54. doi:10.1016/j.neuropsychologia.2014.07.005 
Figure captions

Figure 1. Sample greyscales stimulus from Experiment 1. On average, people viewing this pair are more likely to rate the top bar as darker than the bottom, as the dark side of the gradient appears on the left in this stimulus pair. For many people, including the authors, the bias remains despite the knowledge that the two bars are identical in luminance.

Figure 2. Two representative chimeric face pairs. If the target emotion "anger" was requested via a previous instruction screen, for pair A, a "bottom" choice was predicted to occur more frequently (as the left side of face portrayed anger). As pair B is A's mirror image, "top" was the predicted most frequent choice.

Figure 3. Three sample colourscales stimuli from Experiment 2. The instruction screen is illustrated in the panel above its' companion colourscale figure.

Figure 4. Relative rates of typical bias, comparing right handers to non-right handers. $\mathrm{RR}=$ relative rate of typicality, right handers/non-right handers. $\mathrm{RR}=1.0$ suggest equivalent rates; <1.00 suggest greater incidence of typicality in non-right handers; $>1.00$ suggest the one-tailed hypothesized greater incidence of typicality in right handers. $\mathrm{A}=$ Chimeric faces, $\mathrm{B}=$ Emotional dichotic listening, $\mathrm{C}=$ Greyscales/colourscales. 